\title{
Targeting Cellular Signaling Pathways in Breast Cancer Stem Cells and its Implication for Cancer Treatment
}

\author{
BRUNO RICARDO BARRETO PIRES ${ }^{1 *}$, ÍSIS SALVIANO SOARES DE AMORIM ${ }^{2 *}$, \\ LAYANE DUARTE E SOUZA ${ }^{2}$, JULIANA ALVES RODRIGUES ${ }^{2}$ and ANDRE LUIZ MENCALHA ${ }^{2}$ \\ ${ }^{1}$ Stem Cell Laboratory, Brazilian National Cancer Institute, Rio de Janeiro, RJ, Brazil; \\ ${ }^{2}$ Biophysics and Biometry Department, Roberto Alcantara Gomes Biology Institute, \\ Rio de Janeiro State University, Rio de Janeiro, RJ, Brazil
}

\begin{abstract}
Breast cancer is a public health problem both in developing and developed countries. The breast cancer stem cell (BCSC) hypothesis has grown in the cancer research community. These BCSCs comprise of a small subpopulation of cells within the tumor mass which exhibit stem cell-like characteristics and have emerged as being responsible for tumor development, recurrence and metastasis in BC. The complexity of control of gene expression in BCSC is commonly driven by a myriad of signaling pathways triggered by extracellular signals, mutations and epigenetic control. Thus, some signaling pathways have been highlighted in $B C$, especially those linked to stem cell phenotype, such as nuclear factor-kappa B, signal transducer and activator of transcription 3, wingless-type MMTV integration site family (Wnt)/ $\beta$-catenin, Hedgehog and NOTCH. Moreover, these $B C S C$ s can also be influenced by the tumor microenvironment, for instance, hypoxic areas. Given the importance of signaling pathways and tumor microenvironment for breast cancer, this review focuses on the relationship between cellular signaling and BCSCs and its therapeutic implications.
\end{abstract}

Breast cancer is a public health problem in developing countries, as well as in developed countries. Breast cancer is the second most common type of cancer in women worldwide,

This article is freely accessible online.

*These Authors contributed equally to this article.

Correspondence to: Professor Andre Luiz Mencalha, Universidade do Estado do Rio de Janeiro, Instituto de Biologia Roberto Alcântara Gomes, Departamento de Biofísica e Biometria, Av. 28 de Setembro, 87 fundos - $4^{\circ}$ andar, Vila Isabel - CEP: 20551-030, Brazil. Tel: +55 0212334-2058, e-mail: andre.mencalha@uerj.br

Key Words: Breast cancer, cancer stem cell, signaling, review. representing $22 \%$ of new cancer cases each year (1) and is responsible for more than 522,000 deaths of women annually (2). In developing countries, the 5-year survival rate of patients with breast cancer is around $50-60 \%$ (1).

At the end of the 1970s, the idea of tumor heterogeneity emerged, inferring that tumor masses were composed of differentiated and undifferentiated malignant cells. It was believed that undifferentiated tumor cells were the target of carcinogenesis and kept their basal phenotype growth as malignant stem cells (3). Thereafter, Pierce et al. discussed similarities with normal stem cell phenotypes and the lessdifferentiated tumor cells, postulating that similar phenotypes occurred because of mutations in the tumor stem cell and not because of a dedifferentiation process (4). Some data have demonstrated that this depends on the cancer type: some cancer stem cells arise from the transformation of normal stem cells, whereas other differentiated cells acquire stem cell properties through tumorigenesis $(5,6)$. In fact, several articles have reported that tumors are more complex than expected (6).

The origin of cancer stem cell terminology is still much discussed and some researchers have preferred the term 'tumor-initiating cells' because of the ability of self-renewal and initiating a new whole tumor, like normal stem cells. The first terminology, 'cancer stem cell', was probably given due to the discovery of hematopoietic stem cells, the main source of all differentiated functional blood cells and responsible for leukemia development. These hematopoietic stem cells are represented by a small population characterized by hematopoietic progenitor cell antigen cluster of differentiation $34^{+}\left(\mathrm{CD} 34^{+}\right)$and $\mathrm{CD} 38^{-}$cell surface markers and, in leukemia, these are highly enriched and very much able to transfer disease (7). Independently of the nomenclature, how important are these stem cells for cancer? What are the main characteristics of these cells? What are their special cellular signaling systems which maintain or transform their treatment-resistant and aggressive phenotype? 
It is consolidated that cancer is a multistep process that usually starts with DNA reprogramming by mutations, epigenetics alterations or changes in cellular metabolism (8). These alterations result in a loss of the control of the expression of essential genes responsible for correct cell functions. In this review, we discuss the discovery of BCSC, characterizing them, and explore the current main signaling pathways involved in the BCSC phenotype. We also discuss promising targets of these pathways with therapeutic potential.

\section{The Discovery of BCSCs: The Past}

In solid tumors, a small proportion of cancer cells are clonogenic in vitro and in vivo. To test the tumorigenic potential, uncultured specimens of breast cancer cells from patients were fractioned by flow cytometry, based on the expression of surface molecules, and injected into the mammary fat pads of non-obese diabetic/severe combined immunodeficiency (NOD/SCID) mice. This experiment identified a small subpopulation of the cancer cells which expressed cluster of differentiation 44 (CD44, hyaluronic acid receptor) and had low expression of cluster of differentiation 24 (CD24, a ligand for P-selectin) (i.e. CD44 ${ }^{+} \mathrm{CD} 24^{\text {low/-}}$ ) but were more tumorigenic than $\mathrm{CD} 44^{-} \mathrm{CD} 24^{+}$cells. These cells were termed BCSCs or breast tumor-initiating cells (9). Additionally, the $\mathrm{CD} 44^{+} \mathrm{CD} 24^{\text {low/- }}$ population regenerated grafted tumors with a similar cell heterogeneity as exhibited in the breast tumor. This suggests that tumor heterogeneity present within breast tumors arises via differentiation of BCSCs into non-tumorigenic breast cancer cells (9). As well as these surface markers, the expression of aldehyde dehydrogenase 1 (ALDH1) has also been included as a characteristic of BCSCs (6). These cells have extensively been associated with tumor initiation, progression, metastasis, and resistance to radio/chemotherapy. Consequently, they are also associated with cancer recurrence and therapeutic failure (10).

\section{Understanding BCSC Biology: The Present}

Cellular signaling pathways are responsible for coordinating cellular and molecular characteristics. In BCSCs, this signaling represents the main route for self-renewal, treatment-resistance and aggressiveness. Analogously to the normal stem cells, BCSCs have an intrinsic relationship with embryonic-related pathways, such as wingless-type MMTV integration site family (Wnt)/ $\beta$-catenin, Hedgehog and NOTCH. In addition, inflammatory-related signaling responses, such as nuclear factor-kB (NF-kB) and signal transducer and activator of transcription (STAT) 3 have contributed to this phenotype. Moreover, together with these signaling pathways, hypoxic tumor areas have been described to shelter and stimulate stem cell properties in breast cancer cells.
Wnt/ $\beta$-catenin signaling and BCSC. Wnt $/ \beta$-catenin signaling plays important roles in developmental processes, including patterning and cell fate determination (11). Secreted Wnt, which is palmitoylated by Porcupin, binds to both coreceptors Frizzled and low-density lipoprotein receptorrelated protein 5 and 6 (LRP5/6). Wnt-receptor interaction leads to recruitment of Axin and Dishelved proteins to the cell membrane and induces inhibition of glycogen synthase kinase (GSK)-3 $\beta$ protein. GSK-3 $\beta$ is a negative regulator of the Wnt pathway driven by $\beta$-catenin to proteasomal degradation induced by phosphorylation. Once GSK-3 $\beta$ is inhibited, $\beta$-catenin accumulates in the cytoplasm, moves to the nucleus and acts as co-transcriptional activator together with cAMP response element binding protein (CREB) binding protein (CBP) and T-cell factor/lymphoid enhancing factor (TCF/LEF) transcription factors. The $\beta$-catenin-CPB$\mathrm{TCF} / \mathrm{LEF}$ complex up-regulates oncogenes, such as $c-m y c$, Cyclin D1 and Wnt genes $(11,12)$.

In breast cancer, Wnt signaling is constitutively activated by an autocrine mechanism. In colon cancer and melanoma, genetic alterations of $\beta$-catenin and adenomatous polyposis coli (APC) have been identified; however, it has not had a significant impact on breast cancer cells (13). In BCSC, the role of Wnt signaling has been associated with the maintenance of stem cell properties: inhibition of WNT1 alters the phenotype to $\mathrm{CD} 44^{+} \mathrm{CD} 24^{-} \mathrm{ALDH} 1^{-}$, reducing in vitro and in vivo tumor formation and cellular migration (14).

Zhao et al. suggested that pyruvate kinase isozyme M2 (PKM2) is able to induce mammosphere formation, which could be mediated by promoting $\beta$-catenin transcriptional activity (15). Furthermore, Yeon Kim et al. demonstrated that suppression of GSK3/ $\beta$-catenin signaling via the inhibitory activity of protein kinase D1 (PRKD1) was sufficient to reduce the stemness features of breast cancer cells (16).

The Hedgehog pathway and BCSCs. The hedgehog (Hh) family comprises of Sonic hedgehog (Shh), Indian hedgehog (Ihh) and Desert hedgehog (Dhh). This family encodes signaling molecules that regulate several processes during embryogenesis, including cell proliferation, cell fate determination and patterning. This signaling also bears an important role in maintenance of the stem cell population in adult organisms (17).

The three Hh transcription factors zinc finger protein 1/2/3 (GLI-1/2/3) are held in the cytoplasm in an inactive state by interaction with constitutive cytoplasmic proteins kinesin family member 7 (KIF7) and suppressor of fused [SU(FU)]. In the inactive Hh pathway, patched1 (PTCH1) blocks migration of smoothened (SMO), a G protein-coupled receptor, to the cell membrane. SMO is responsible for transduction of Hh signaling inside the cell by coordinating activation of GLI transcription factors. The Hh protein released by cancer cells contributes to enhancing the activity 
of stromal cells from the tumor microenvironment (18). Once the ligand $\mathrm{Hh}$ is secreted, it binds to $\mathrm{PTCH} 1$ receptor on responding cells, allowing SMO activation by its migration to the cell membrane where it starts $\mathrm{Hh}$ signal transduction. Activated SMO is phosphorylated by casein kinase-1 (CK1) and protein kinase A (PKA) and becomes able to remove GLI from KIF7-SUFU, Hh repressor proteins. Transcription factor GLI is then released to translocate into the nucleus, resulting in the expression of target genes $(17,19)$.

Several pieces of evidence suggest an important role of the Hh pathway in breast cancer, for example, Hh overexpression or PTCH1 mutation/polymorphism results in constitutive activation of SMO and up-regulation of this signaling pathway (20). Moreover, these alterations have been linked to a more aggressive phenotype, such as a triple-negative breast cancer (20). Hh signaling is essential for maintaining the BCSC phenotype (21) and regulating self-renewal (22). Current data support the importance of Hh signaling breast cancer and pancreatic cancer stem cells, and to chronic myeloid leukemia, in which the Hh proteins are often upregulated, promoting growth and self-renewal $(23,24)$.

He et al. reported that MCF-7 breast cancer mammospheres expressed increased levels of $\mathrm{Hh}$ pathway members in comparison to MCF-7 cells cultured as monolayers (25). They also observed positive correlation between the expression of SMO and GLI1 with BCSC markers CD $44^{+} \mathrm{CD} 24^{-}$.

Memmi et al. demonstrated that p63 (other important factor for promoting self-renewal in normal epithelial stem cells) contributes to the maintenance of BCSCs, using in vivo models (26). This transcription factor is responsible for upregulates the levels of some Sh signaling members in BCSC context.

$N F-k B$ signal transduction pathway and BCSCs. The NF$\mathrm{KB}$ family consists of five conserved proteins, RELA (p65), RELB, c-REL, p50 and p52. All of them share the conserved REL homology domain (RHD) which is responsible for DNA binding, dimerization and association with the repressor protein inhibitor of kappa B (IкB). The NF-kB pathway comprises the canonical and the noncanonical pathways. The canonical pathway is downstream of the pro-inflammatory cytokine receptors, such as tumor necrosis factor alpha (TNF- $\alpha$ ), Interleukin 1 beta (IL-1 $\beta$ ); toll-like receptor (TLR) family; T-cell receptor (TCR) and $\mathrm{B}$-cell receptor (BCR) that ultimately leads to ubiquitindependent degradation of the repressor $\operatorname{IkB} \alpha$ though phosphorylation by the IkB kinase (IKK) complex. IкB $\alpha$ degradation releases the p65-p50 dimer to translocate into the nucleus and activate the transcription target genes $(27$, 28). The non-canonical pathway is downstream of CD40L, receptor activator for nuclear factor $\mathrm{kB}$ (RANK) and $\mathrm{B}$ cell-activating factor receptor (BAFF-R) pathways that leads to NF-kB-inducing kinase (NIK) activation, which phosphorylates the homodimer IKK $\alpha$ that in turn phosphorylates the p100 subunit to be processed into p52. This ultimately leads to nuclear translocation of p52-RELB dimer $(27,29)$.

NF-kB transcription factors play essential roles in biological processes, including differentiation during embryogenesis, inflammation, immunological responses, cell proliferation and survival (30). NF- $\mathrm{kB}$ is a regulator of innate immunity and it is responsible for inducing the expression of cyclooxygenase 2 (COX2) and nitric oxide synthase (NOS), inflammatory cytokines such as IL-1, IL-6, IL-8 and TNF- $\alpha$, chemokines such as $\mathrm{C}-\mathrm{C}$ motif chemokines ligand 2 (CCL2) and C-X-C motif chemokines ligand 2 (CXCL8) (31). It is also described as inhibiting the intrinsic apoptotic pathway by inducing the expression of several antiapoptotic genes, including the B-cell lymphoma 2 (BCL2) family [BCL2, BCL-xl and Survivin (BIRC5)]; for inducing the proliferation through up-regulation of cyclin D1, the key cyclin of $\mathrm{G}_{1} / \mathrm{S}$ phase, and by increasing angiogenesis through vascular endothelial growth factor (VEGF) and IL6 upregulation (27). In addition, $\mathrm{NF}-\mathrm{kB}$ is a key factor in both radio- and chemoresistance (27).

The constitutive activation of NF-kB has been reported in several types of cancer, including breast cancer (32). In breast tumors, constitutive activation of NF-kB contributes to cellular proliferation, angiogenesis and evasion of apoptosis, and is mostly described in human epidermal growth factor receptor 2 (HER2/neu) and triple-negative tumors. Liu et al. reported that $\mathrm{NF}-\mathrm{kB}$ is required for initiation of HER2-positive murine mammary tumor growth (33). This transcription factor governs the initiation of HER2 tumors and its inhibition was sufficient to reduce the CD44+ (marker of human cancer stem cells) cell population and reduced the tumor microvessel density in models. When HER2 murine cells expressed IkB $\alpha$ mutant, which constitutively repressed the NF-kB pathway, a dramatic reduction in mammosphere numbers and down-regulation of embryonic stem cell factors sex determining region Y-box 2 (SOX2) and homeobox transcription factor Nanog (NANOG) (33) was observed. These findings together provide the evidence that the NF-kB pathway contributes to BCSC phenotype. Pratt et al. reported that $N F-k B$ is activated during differentiation of luminal progenitor cells and is required for the early steps of tumorigenesis in breast cancer (34). The high level of $\mathrm{NF- \textrm {KB }}$ found in triplenegative tumors is due to epidermal growth factor receptor (EGFR) overexpression, which is positive in part of this group (35) and ultimately activates NF-kB (36). In a recent report, Kendellen et al. showed consistently that the canonical and non-canonical NF-kB signaling is required for self-renewal and to form xenograft tumors for triple-negative breast cancer cells (37). 
Interestingly, Nakshatri et al. reported that progression of rat mammary carcinoma from an estrogen receptor (ER)positive, non-malignant phenotype to an ER-negative, malignant phenotype was accompanied by a constitutive activation of NF-kB signaling (38). These findings were in concordance with Wang et al., who described the repression of RELB in ER-positive breast cancer cells (39). Both studies reinforce the significance of $N F-\mathrm{kB}$ signaling to hormone-independent breast cancer.

$\mathrm{NF}-\mathrm{kB}$ signaling is considered pivotal in the cancer stem cell context for generating secondary mammospheres in $\mathrm{CD}_{4}{ }^{+}$murine cells and seems to be a key player in resistance to therapies (32). Hence, the NF- $\mathrm{KB}$ pathway is a promising target for cancer therapy.

The notch pathway and BCSCs. The translocation-associated Notch protein (NOTCH) signaling controls self-renewal and asymmetric divisions of normal stem cells and appears to be reactivated in epithelial cells to contribute to tumorigenesis in the earliest cancer phases. Notch signaling is mainly promoted by cell-to-cell interaction: it is triggered by contact of Notch receptor (represented by NOTCH1, 2, 3 and 4) present in the surface of the receiving cell, with Delta or Jagged proteins, located on the surface of sending cells. The Delta/Jagged-Notch interaction promoting release of Notch intracellular domain (NICD), cleaved by A-disintegrin and metalloproteinase (ADAM) proteases and by enzymatic complex $\gamma$-secretase. Once cleaved, NICD diffuses into nucleus, interacts with the co-activators Mastermind (MAM) and p300 to regulate Notch target genes $(40,41)$.

Clarck et al. reported the role of NOTCH1 expression in breast epithelial stem cells in regulating asymmetrical cell division and supposed that it was the BCSC source (42). Furthermore, NOTCH1 expression was up-regulated in $\mathrm{CD} 44^{+} \mathrm{CD} 24^{\text {low/- }}$ breast cancer cells and has been associated with radioresistance (43). Sansone et al. also demonstrated that mammosphere self-renewal induced by IL-6 was NOTCH3 signaling-dependent (44). The findings of D'Angelo et al. confirmed the role of the Notch pathway in the self-renewal ability of BCSCs when they demonstrated that breast tumor cells with high activity of Notch overexpressed cancer stem cell markers and significantly increased both mammosphere formation (in vitro) and in vivo tumor-forming capabilities (45).

Hypoxia signaling and BCSCs. The hypoxia-inducible factor (HIF) is a heterodimer composed of one alpha subunit, which is regulated by oxygen, and a beta subunit referred to as constitutive, known as aryl hydrocarbon receptor nuclear translocator (ARNT) (46). There are three alpha subunits isoforms: HIF- $1 \alpha$, HIF-2 $\alpha$ and HIF-3 $\alpha$. While the HIF- $2 \alpha$ subunit is restricted to certain tissues, HIF- $1 \alpha$ is widely expressed, being the first to respond to hypoxia $(47,48)$. The function of HIF-3 $\alpha$ is not fully known, however, a splice variant is known to be able to inhibit HIF-1 $\alpha$ activity (49). HIF-1 $\alpha$ activation occurs under condition of low oxygen, known as hypoxia. At normal oxygen concentrations, known as normoxia, prolyl hydroxylase enzymes (PHDs) drive hydroxylation of HIF- $1 / 2 \alpha$ proline amino acid residues, which are then recognized by von Hippel Lindau (VHL) protein. This hydroxylation results in proteolytic degradation of HIF-1 $\alpha$ (50).

In hypoxia, HIF-1 $\alpha$ is not hydroxylated by PHDs, which makes it stable in the cytoplasm. HIF-1 $\alpha$ moves to the nucleus, where it dimerizes with HIF-1 $\beta$ to form an active heterocomplex able to regulate the expression of several genes (51). These target genes allow the cell to survive in the hostile environment represented by a low level of oxygen, acidic and with nutrient scarcity $(52,53)$.

Hypoxia is a hallmark of solid tumors, in which the blood supply is not sufficient to meet the demand of the growing tumor mass (54). It is known that a hypoxic environment has a negative clinical impact, since hypoxic cells are more radiotherapy- and chemotherapy-resistant, contributing to poor prognosis (55-58). The relationship between hypoxia and poor prognosis is commonly associated with posttreatment relapse and metastasis. In part, it is probably justified by the observation that cancer stem cells are located in hypoxic microenvironment areas, which confers a high metastatic potential and increases resistant to conventional treatments in these cells. Hypoxic cancer stem cells are mainly responsible for repopulating in situ and distant tumors after treatment $(59,60)$.

Interestingly, breast cancer cells may acquire cancer stem cell phenotype after exposure to hypoxia $(61,62)$. This phenomenon is promoted through transcription factors responsive to hypoxia, HIF- $1 \alpha$ and HIF- $2 \alpha$, able to induce cell tumor dedifferentiation to BCSC characteristics (63). This process comprises HIF- $1 \alpha$ and NOTCH1 interaction, which leads to maintenance of the undifferentiated state of the stem cell, such as occurs in embryonic stem cells (64). Schwab et al. showed that HIF- $1 \alpha$ interferes in BCSC viability regulation; supporting the formation of mammospheres and the increase of the $\mathrm{CD} 44^{+} \mathrm{CD} 24^{\text {low/- }}$ population in vivo by up-regulating CD133 expression and cellular markers of basal phenotype in breast tumors, which are Notch pathway targets (65). These results suggest that the underlying mechanism might involve regulation of HIF$1 \alpha$-dependent components present in the Notch signaling pathway. Moreover, in vitro experiments carried out under hypoxic conditions using triple-negative breast cancer cell lines showed an increase of CD44 expression mediated by HIF- $1 \alpha$, described as a BCSC marker (66). In turn, HIF-2 $\alpha$ also contributes to BCSC phenotype by directly promoting expression of octamer-binding transcription factor 4 (OCT4), that is involved in maintaining stem cell properties (67). 
Additionally, hypoxia increases the expression of other factors involved in stem cell maintenance, such as NANOG, SOX2 and Kruppel-like factor 4 (KLF4) in several tumor cell lines (68).

Xing et al. reported that hypoxia significantly increased the expression of NOTCH1 ligand, JAGGED2, in breast cancer cells present in the invasive tumor front of migratory process (69). Furthermore, JAGGED2 expression was also increased in hypoxic regions of bone cells and was mainly associated with self-renewal. Since bone is a major site of metastasis of breast cancer, bone hypoxic areas are suitable niches for BCSC metastasis, promoting BCSC self-renewal.

STAT3 pathway and BCSCs. STAT proteins comprise a family of cytoplasm transcription factors that mediate intracellular signaling triggered by many molecules and thereby transmit it to nucleus. Among STAT proteins, STAT3 intermediates extracellular signals stimulated by cytokines, mainly IL-6, growth factors and other molecules (70). Briefly, the receptor tyrosine kinase Janus kinases (JAK) recruit STAT3, which dimerizes and is translocated to the nucleus where it recognizes specific DNA sequences and activates the transcription of target genes. This transcription factor regulates many cellular processes, including proliferation, apoptosis, invasion, angiogenesis and metastasis (71).

In breast cancer, STAT3 protein is constitutively activated and much evidence suggests that aberrant STAT3 signaling promotes cancer initiation and progression (70). Interestingly, STAT3 is highly involved in BCSC development and progression and its persistent activity is crucial to stem cell-like and mesenchymal properties during metastasis (72-74). Recently, STAT3 was also described as pivotal in inflammatory signaling and maintenance of BCSCs by controlling self-renewal and differentiation, which confers a poor prognosis and highlights its therapeutic potential $(70,74)$.

A great amount of evidence supports the role of STAT3 in $\mathrm{BCSCs}$, although its relevance in breast cancer initiation and progression is not completely known (75). The BCSC phenotype is regulated by many signal transduction pathways, which include IL-6-JAK2-STAT3 pathway, which is preferentially activated in $\mathrm{CD} 44^{+} \mathrm{CD} 24^{-} \mathrm{BCSCs}$ when compared to other breast tumor cells $(72,76)$. However, the expression of other cytokines, such as IL- $1 \alpha$ and IL-8, is also positively correlated with the expression of $\mathrm{CD} 44^{+} \mathrm{CD} 24^{\text {low/ }}$ markers in breast cancer cell lines (76).

Moreover, the classical co-receptor for growth and angiogenic factors in inflammatory response stimulus CD138 has been described as responsible for linking STAT3, Wnt and NF-kB signaling to modulate the BCSC phenotype (77). The self-renewal observed in BCSCs was referred to as being epigenetically regulated in the IL-6-STAT3phosphatidylinositol 3-kinase (PI3K) pathway (78).
Regarding breast cancer treatment, current studies have been elucidating the relevance of STAT3 signaling to BCSC maintenance. Wang et al. proposed that STAT3 signaling might mediate tamoxifen resistance in BCSCs by upregulation of STAT3 in $\mathrm{CD} 44^{+} \mathrm{CD} 24^{\text {low/- }}$ subpopulation of tamoxifen-resistant MCF-7 cells (79). In addition, MDAMB-231 stem-like cells treated with the antibiotic salinomycin resulted in blockage of cell migration and invasion by inhibition of STAT3 activation which consequently led to a down-regulation of its regulatory targets cyclin-D1, matrix metallopeptidase 9 (MMP9) and 2 (MMP2) (80). A recent study reported that a natural product obtained from fermented blueberry preparation (polyphenolenriched blueberry preparation) reduced the formation of cancer stem cells in MDA-MB-231 and MCF-7 cells when they were cultured both in vitro and in vivo through modulation of IL-6-STAT3 signaling (74).

Zhang et al. showed that the ectopic expression of microRNA-7 significantly down-regulated the expression and activation of STAT3 through inhibition of SET domain bifurcated 1 (SETDB1), which result in inhibition of epithelial-mesenchymal transition properties in $\mathrm{CD} 44^{+} \mathrm{CD} 24^{-}$epithelial-specific antigen-positive MDA-MB231 cells and of metastasis in vivo (75). Together, the evidence corroborates the relevance of the STAT3 pathway to BCSC development and maintenance and its potential as a therapeutic target.

\section{Perspectives for BCSCs: The Future}

Based in BCSC characteristics, there is a growing interest in understanding BCSC biology, which could provide more information about potential therapy targets. Were these targets identified, the elimination of resistant cells responsible for maintaining the tumor would be possible. Ultimately, it might improve treatment efficacy and have positive outcomes for patients with breast cancer. Thereby, the search for relevant potential molecular targets should be encouraged.

Recent research related to the embryonic pathways Wnt, $\mathrm{Hh}$ and Notch have evaluated potential inhibitors. Regarding the Wnt pathway, LGK974, a Porcupine inhibitor, blocks WNT palmitoylation (81), and PRI-724, CREB binding protein/catenin antagonist (82), have shown interesting results and are in phase I trial for breast cancer and other solid tumors.

Jang et al. developed the $\mathrm{WNT} / \beta$-catenin inhibitor CWP232228. This small molecule showed satisfactory results through preferential inhibition of growth of BCSCs and other breast tumor cells (83).

The inhibition of $\mathrm{Hh}$ signaling pathway has shown promising results for BCSC therapy. Fu et al. reported that salinomycin, a carboxylic polyether ionophore, was 
selectively cytotoxic to BCSCs in MCF-7 mammospheres instead of monocultured MCF-7 cells. The observed cytotoxicity was mediated by inhibition of Hh signaling since its components expression decreased after treatment (84).

Moreover, one promising inhibitor of SMO, called LDE225, is in a phase II trial for breast cancer and other solid tumors (85). The most promising inhibitors for Notch signaling, the compounds MK-0752 and PF-03084014, aiming for the inhibition of $\gamma$-secretase activity, are in Phase I trial $(86,87)$.

Furthermore, Simões et al. demonstrated that anti-estrogen therapy using Tamoxifen or Fulvestrant, increased the activity of the BCSCs though activation of NOTCH4-JAG1 axis (88). The same group also showed that a hormone therapy combined with NOTCH4 inhibition, using $\gamma$ secretase inhibitor RO4929097, might abrogate anti-estrogen therapy resistance.

A recent study has suggested that capsaicin, a compound derived from chilli peppers is able to induce cell death in BCSCs via apoptosis, in a dose-dependent manner. The mechanism could be via inhibition of NICD translocation into the nucleus, reducing its regulatory activity (89).

In order to avoid intestinal toxicity provoked by inhibition of all Notch receptors promoted by $\gamma$-secretase inhibitors, new specific antibodies against certain receptors have been developed (90). Yen et al. demonstrated the effectiveness of anti-NOTCH2/3 (OMP-59R5, tarextumab) in reducing the proportion of BCSCs using in vivo models (91).

Anticancer research has highlighted a number of NF-kB inhibitors. The protease inhibitor bortezomib has shown interesting results in treatment of refractory myeloma to inhibit degradation of the IkB complex, keeping NF-kB transcription factor in the cytoplasm (92). Additionally, a more promising inhibitor is dehydroxymethylepoxyquinomicin, reported to inhibit the development of tumors, including breast cancer, in murine models (93). Recently, this compound was described as disturbing the epithelialmesenchymal transition found in aggressive phenotypes of breast cancer (Pires et al., unpublished data), being able to inhibit mammosphere formation in HER2 cells (94). Overall, $\mathrm{NF}-\mathrm{kB}$ inhibition is an attractive field in cancer therapy.

Given the role of hypoxia in tumor progression and the formation of a tumor stem cell niche in breast cancer (59, $60)$, novel therapeutic approaches that target hypoxia factors, especially HIF- $1 \alpha$ and HIF-2 $\alpha$, are of interest (58). Combination of conventional chemotherapies with hypoxia factor inhibitors appears to be promising for therapeutic alternatives, including BCSC, thereby preventing the onset of metastasis and recurrence after treatment $(62,65)$. Lock et al. reported that inhibition of the expression or activity of carbonic anhydrase IX (CA-IX), which is one of the genes regulated by hypoxia, resulted in inhibition of the growth of metastatic BCSCs under hypoxia. CA-IX is a critical mediator of BCSC growth in hypoxic niches (95). Therefore, CA-IX represent a valid therapeutic target for selectively reducing BCSCs.

In addition to direct inhibition of hypoxia factors, many treatments aim at molecular targets related to hypoxia, such as anti-VEGF therapies. Although antiangiogenic therapies that target VEGF (VEGF-neutralizing antibody bevacizumab) or its receptor (VEGF receptor tyrosine kinase inhibitors sorafenib and sunitinib) are used in the treatment of breast cancer (96), their results are usually transient and involve recurrence of a more aggressive disease $(97,98)$.

Furthermore, preclinical studies have demonstrated that antiangiogenic therapy is able to generate intratumoral hypoxia, which promotes an increase in the BCSC population, due to HIF- $1 \alpha$-dependent activation of WNT- $\beta$ catenin pathway involved in cancer stem cell self-renewal $(99,100)$. This reinforces the idea that in order to achieve an effective therapy, combinations of angiogenic inhibitors with drugs targeting BCSCs are necessary (99). However, in vitro studies showed that the combination of antiangiogenic agent with multi-kinase inhibitor sorafenib associated with ionizing radiation was able to inhibit BCSCs preferably in hypoxic conditions, and suggested that this inhibition may be a consequence of reduction of HIF-1 $\alpha$ expression (101). Harrison et al. demonstrated through in vitro and in vivo experiments that hypoxia affects BCSC activities differently according to ER status (102). In ER+ tumors, hypoxia led to increased mammosphere formation and tumor numbers from BCSCs in an HIF- $1 \alpha$ and NOTCH1-dependent fashion. These characteristics were reversed using a Notch inhibitor.

On the other hand, since bone is a major site of metastasis of breast cancer, bone hypoxic areas are suitable niches for BCSC metastasis, promoting BCSC self-renewal, associated with JAGGED2 expression. Therefore, new therapeutic approaches that target JAGGED2 may have a significant effect by targeting metastatic BCSCs. (69).

Regarding STAT3 signaling, in HER2+ breast cancer subtype, Chung et al. demonstrated that HER2 signaling leads to the activation of STAT3, with subsequent upregulation of stem cell markers, such as OCT4, SOX2 and CD44. They showed that the expression of these markers was down-regulated and spheroid formation was abolished after STAT3 inhibition by stattic. Moreover, they showed that combined treatment of Herceptin with stattic led to a higher rate of apoptosis than the separate treatments and this may help overcome the resistance derived from the enriched of cancer stem cells in breast tumors (103).

Mathematical models also have been useful in studying the population of cancer stem cells under targeted therapy. Sehl et al. recently reported that slowing self-renewal and disrupting the positive feedback loop between IL-6, STAT3 activation and NF-kB signaling by simultaneous inhibition of IL-6 and HER2 is the most effective combination of 

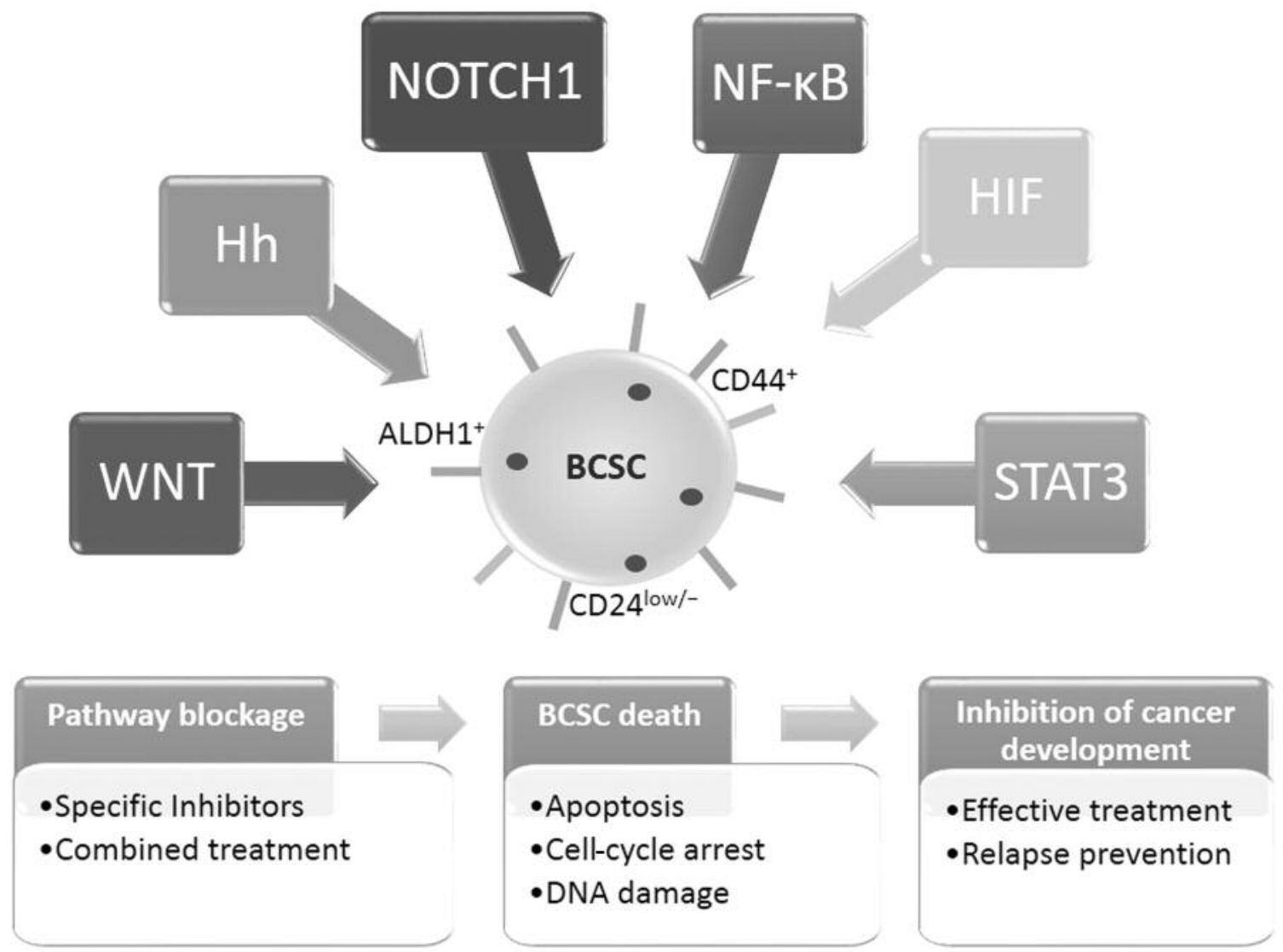

Figure 1. The wingless-type MMTV integration site family (W)- $\beta$-catenin, Hedgehog (Hh), NOTCH1, nuclear factor-kappa B (NF-kB), hypoxiainducible factor (HIF) and signal transducer and activator of transcription (STAT3) signaling cooperatively induce, in some cases, the breast cancer stem cell (BCSC) phenotype. This is characterized by stem cell features, such as self-renewal, and the following expression profile: cluster of differentiation $44(\mathrm{CD} 44)^{+}, \mathrm{CD} 24$ low/- and aldehyde dehydrogenase $1(\mathrm{ALDH1})^{+}$. Treatments based on blockage of these signaling pathways is promising, since they might induce BCSC death in different ways. Ultimately, this could result in a more effective treatment against cancer development and prevention of relapse after conventional therapy.

therapies to eliminate both mesenchymal and epithelial populations of BCSCs (104). The results show an excellent agreement with experimental data from cell line and mouse xenograft studies, highlighting the combined efficacy of HER 2 and IL-6 blockade. Nevertheless, the authors clarify that the complexities of the microenvironment limit the ability of analytic models and emphasize the necessity for more detailed models of simulation (104).

A recent study linked tumor growth in vivo and metastasis to signaling driven by STAT3, PI3K/AKT and MAPK/ERK pathways. This study suggested that cancer stem cell growth and aggressiveness are associated with inflammatory cellular signaling (74).

These data support the effectiveness of some combined therapies and pathways as a new approach to combat BCSC development (Figure 1). Therefore, targeting these pathways could make treatments against breast cancer more effective, aiming at the source of disease.

\section{Conclusion}

The BCSC concept suggests the existence of subpopulations of neoplastic cells with increased tumor-initiating ability and resistance to therapies. Understanding the biology of BCSCs and the mechanisms that support them in breast cancer could help improve tumor treatment and prevent recurrence and metastasis. Therefore, therapeutic targeting in specific signaling pathway of these cells may remove residual disease and become an important component of a multimodality treatment.

Targeting the stem cell niche to eradicate BCSCs represents a new area of therapeutic development. The complex nature of many features of the stem cell niche, including both intracellular signals and microenvironment creates a challenge in choosing which elements to target, and whether alone or in combination. In this sense, mathematical modeling combined with experimental validation can be an alternative for optimizing the development of safe and 
effective therapies that target the cancer stem cell and its niche. Many studies have focused on different targets concomitantly to eradicate breast cancer stem cells, but ultimately, is it possible to achieve this goal?

\section{Conflicts of Interest}

The Authors declare no conflict of interest.

\section{Acknowledgements}

All individuals listed as authors contributed substantially to the review drafting or revising.

\section{References}

1 Instituto Nacional de Câncer: Estimate/2014 - Cancer Incidence in Brazil. 2014. http://www.saude.sp.gov.br/resources/ ses/perfil/gestor/homepage/outros-destaques/estimativa-deincidencia-de-cancer-2014/estimativa_cancer_24042014.pdf. Accessed 15 June 2016.

2 International Agency for Reseach on Cancer: GLOBOCAN 2012: Estimated Cancer Incidence, Mortality and Prevalence Worldwide. 2012. http://globocan.iarc.fr/Pages/fact_sheets_ cancer. Accessed 15 June 2016.

3 Pierce GB: Relationship between differentiation and carcinogenesis. J Toxicol Environ Health 2: 1335-1342, 1977.

4 Pierce GB, Nakane PK, Martinez-Hernandez A and Ward JM: Ultrastructural comparison of differentiation of stem cells of murine adenocarcinomas of colon and breast with their normal counterparts. J Natl Cancer Inst 58: 1329-1345, 1977.

5 Bjerkvig R, Tysnes BB, Aboody KS, Najbauer J and Terzis AJA: Opinion: the origin of the cancer stem cell: current controversies and new insights. Nat Rev Cancer 5: 899-904, 2005.

6 Pattabiraman DR and Weinberg RA: Tackling the cancer stem cells - what challenges do they pose? Nat Rev Drug Discov 13: 497-512, 2014.

7 Lapidot T, Sirard C, Vormoor J, Murdoch B, Hoang T, Caceres-Cortes J, Minden M, Paterson B, Caligiuri M a and Dick JE: A cell initiating human acute myeloid leukaemia after transplantation into SCID mice. Nature 367: 645-648, 1994.

8 Beckmann MW, Niederacher D, Schnüren HG, Gusterson BA and Bender HG: Multistep carcinogenesis of breast cancer and tumour heterogeneity. J Mol Med 75: 429-439, 1997.

9 Al-Hajj M, Wicha MS, Benito-Hernandez A, Morrison SJ and Clarke MF: Prospective identification of tumorigenic breast cancer cells. Proc Natl Acad Sci USA 100: 3983-3988, 2003.

10 Al-Ejeh F, Smart CE, Morrison BJ, Chenevix-Trench G, López JA, Lakhani SR, Brown MP and Khanna KK: Breast cancer stem cells: Treatment resistance and therapeutic opportunities. Carcinogenesis 32: 650-658, 2011.

11 Howe LR and Brown AMC: WNT signaling and breast cancer. Cancer Biol Ther 3: 36-41, 2004.

12 MacDonald BT, Semenov MV and He X: SnapShot: WNT/ $\beta$ catenin signaling. Cell 131: 1204, 2007.
13 Giles RH, Van Es JH and Clevers H: Caught up in a WNT storm: WNT signaling in cancer. Biochim Biophys Acta - Rev Cancer 1653: 1-24, 2003.

14 Jang G-B, Kim J-Y, Cho S-D, Park K-S, Jung J-Y, Lee H-Y, Hong I-S and Nam J-S: Blockade of WNT/ $\beta$-catenin signaling suppresses breast cancer metastasis by inhibiting CSC-like phenotype. Sci Rep 5: 12465, 2015.

15 Zhao Z, Song Z, Liao Z, Liu Z, Sun H, Lei B, Chen W and Dang $\mathrm{C}$ : PKM2 promotes stemness of breast cancer cell by through WNT/ $\beta$-catenin pathway. Tumor Biol 37: 4223-4234, 2016.

16 Yeon Kim D, Young Park E, Chang E, Kang H-G, Koo Y, Ji Lee E, Yeong Ko J, Kyung Kong H, Chun K-H and Hoon Park $\mathrm{J}$ : A novel miR-34a target, protein kinase D1, stimulates cancer stemness and drug resistance through GSK3/ $\beta$-catenin signaling in breast cancer. Oncotarget 7: 14791-14802, 2016.

17 Chen MH, Wilson CW and Chuang PT: SnapShot: hedgehog signaling pathway. Cell 130: 386, 2007.

18 Ruiz i Altaba A: Hedgehog signaling and the GLI code in stem cells, cancer, and metastases. Sci Signal 4: pt9, 2011.

19 Lum L and Beachy PA: The Hedgehog response network: sensors, switches, and routers. Science 304: 1755-1759, 2004.

20 Tao Y, Mao J, Zhang Q and Li L: Overexpression of Hedgehog signaling molecules and its involvement in triple-negative breast cancer. Oncol Lett 2: 995-1001, 2011.

21 Tanaka H, Nakamura M, Kameda C, Kubo M, Sato N, Kuroki S, Tanaka $M$ and Katano M: The Hedgehog signaling pathway plays an essential role in maintaining the $\mathrm{CD} 44^{+} \mathrm{CD} 24^{-/ \text {low }}$ subpopulation and the side population of breast cancer cells. Anticancer Res 29: 2147-2157, 2009.

22 Liu S and Wicha MS: Targeting breast cancer stem cells. J Clin Oncol 28: 4006-4012, 2010.

23 Li C, Heidt DG, Dalerba P, Burant CF, Zhang L, Adsay V, Wicha M, Clarke MF and Simeone DM: Identification of pancreatic cancer stem cells. Cancer Res 67: 1030-1037, 2007.

24 Su W, Meng F, Huang L, Zheng M, Liu W and Sun H: Sonic hedgehog maintains survival and growth of chronic myeloid leukemia progenitor cells through $\beta$-catenin signaling. Exp Hematol 40: 418-427, 2012.

25 He M, Fu Y, Yan Y, Xiao Q, Wu H, Yao W, Zhao H, Zhao L, Jiang Q, Yu Z, Jin F, Mi X, Wang E-H, Cui Z, Fu L-W, Chen J and Wei $\mathrm{M}$ : The Hedgehog signaling pathway mediates drug response of MCF-7 mammosphere cells and breast cancer patients. Clin Sci (Lond) 129: 809-822, 2015.

26 Memmi EM, Sanarico AG, Giacobbe A, Peschiaroli A, Frezza V, Cicalese A, Pisati F, Tosoni D, Zhou H, Tonon G, Antonov A, Melino G, Pelicci PG and Bernassola F: p63 Sustains selfrenewal of mammary cancer stem cells through regulation of Sonic Hedgehog signaling. Proc Natl Acad Sci USA 112: 34993504, 2015.

27 Gupta S, Sundaram C, Reuter S and Aggarwal B: Inhibiting NF-kB activation by small molecules as a therapeutic strategy. Biochim Biophys Acta 1799: 775-787, 2011.

28 Vandenabeele P, Galluzzi L, Vanden Berghe T and Kroemer G: Molecular mechanisms of necroptosis: an ordered cellular explosion. Nat Rev Mol Cell Biol 11: 700-714, 2010.

29 Sun S-C: Non-canonical NF-kB signaling pathway. Nat Publ Gr 21: 71-8571, 2010.

30 Karin M: Nuclear factor-kappaB in cancer development and progression. Nature 441: 431-436, 2006. 
31 Colotta F, Allavena P, Sica A, Garlanda C and Mantovani A: Cancer-related inflammation, the seventh hallmark of cancer: Links to genetic instability. Carcinogenesis 30: 1073-1081, 2009.

32 Shostak K and Chariot A: NF-kB, stem cells and breast cancer: the links get stronger. Breast Cancer Res 13: 214, 2011.

33 Liu M, Sakamaki T, Casimiro MC, Willmarth NE, Quong AA, Ju X, Ojeifo J, Jiao X, Yeow WS, Katiyar S, Shirley LA, Joyce D, Lisanti MP, Albanese C and Pestell RG: The canonical NFkappaB pathway governs mammary tumorigenesis in transgenic mice and tumor stem cell expansion. Cancer Res 70: 1046410473, 2010.

34 Pratt M a C, Tibbo E, Robertson SJ, Jansson D, Hurst K, PerezIratxeta C, Lau R and Niu MY: The canonical NF-kappaB pathway is required for formation of luminal mammary neoplasias and is activated in the mammary progenitor population. Oncogene 28: 2710-2722, 2009.

35 Voduc KD, Cheang MCU, Tyldesley S, Gelmon K, Nielsen TO and Kennecke H: Breast cancer subtypes and the risk of local and regional relapse. J Clin Oncol 28: 1684-1691, 2010.

36 Biswas DK and Iglehart JD: Linkage between EGFR family receptors and nuclear factor kappaB (NF-kappaB) signaling in breast cancer. J Cell Physiol 209: 645-652, 2006.

37 Kendellen MF, Bradford JW, Lawrence CL, Clark KS and Baldwin a S: Canonical and non-canonical NF-kB signaling promotes breast cancer tumor-initiating cells. Oncogene 33: 1297-1305, 2014.

38 Nakshatri H, Bhat-Nakshatri P, Martin D a, Goulet RJ and Sledge GW: Constitutive activation of NF-kappaB during progression of breast cancer to hormone-independent growth. Mol Cell Biol 17: 3629-3639, 1997.

39 Wang X, Belguise K, Kersual N, Kirsch KH, Mineva ND, Galtier F, Chalbos D and Sonenshein GE: Oestrogen signalling inhibits invasive phenotype by repressing RelB and its target BCL2. Nat Cell Biol 9: 470-478, 2007.

40 Bray S: Notch signalling: a simple pathway becomes complex. Nat Rev Mol Cell Biol 7: 678-689, 2006.

41 Ilagan MX and Kopan R: SnapShot: Notch signaling pathway. Cell 6: 1246, 2007.

42 Clarke RB, Anderson E, Howell A and Potten CS: Regulation of human breast epithelial stem cells. Cell Prolif 36(Suppl 1): 45-58, 2003.

43 Phillips TM, McBride WH and Pajonk F: The response of CD24-/low/CD44+ breast cancer-initiating cells to radiation. J Natl Cancer Inst 98: 1777-1785, 2006.

44 Sansone P, Storci G, Tavolari S, Guarnieri T, Giovannini C, Taffurelli M, Ceccarelli C, Santini D, Paterini P, Marcu KB, Chieco $\mathrm{P}$ and Bonafè M: IL-6 triggers malignant features in mammospheres from human ductal breast carcinoma and normal mammary gland. J Clin Invest 117: 3988-4002, 2007.

45 D'Angelo RC, Ouzounova M, Davis A, Choi D, Tchuenkam SM, Kim G, Luther T, Quraishi AA, Senbabaoglu Y, Conley SJ, Clouthier SG, Hassan KA, Wicha MS and Korkaya H: Notch reporter activity in breast cancer cell lines identifies a subset of cells with stem cell activity. Mol Cancer Ther 14: 779-787, 2015.

46 Wang GL, Jiang BH, Rue EA and Semenza GL: Hypoxiainducible factor 1 is a basic-helix-loop-helix-PAS heterodimer regulated by cellular O2 tension. Proc Natl Acad Sci USA 92: 5510-5514, 1995.
47 Keith B, Johnson RS and Simon MC: HIF1 $\alpha$ and HIF2 $\alpha$ : sibling rivalry in hypoxic tumour growth and progression. Nat Rev Cancer 12: 9-22, 2012.

48 Wiesener MS, Jürgensen JS, Rosenberger C, Scholze CK, Höstrup JH, Warnecke C, Mandriota S, Bechmann I, Frei UA, Pugh CW, Ratcliffe PJ, Bachmann S, Maxwell PH and Eckardt KU: Widespread hypoxia-inducible expression of HIF-2alpha in distinct cell populations of different organs. FASEB J 17: 271-273, 2003.

49 Maynard MA, Qi H, Chung J, Lee EHL, Kondo Y, Hara S, Conaway RC, Conaway JW and Ohh M: Multiple splice variants of the human HIF-3 $\alpha$ locus are targets of the von Hippel-Lindau E3 ubiquitin ligase complex. J Biol Chem 278: 11032-11040, 2003

50 Ohh M, Park CW, Ivan M, Hoffman M a, Kim TY, Huang LE, Pavletich N, Chau V and Kaelin WG: Ubiquitination of hypoxia-inducible factor requires direct binding to the betadomain of the von Hippel-Lindau protein. Nat Cell Biol 2: 423427, 2000.

51 Maxwell PH, Pugh CW and Ratcliffe PJ: Activation of the HIF pathway in cancer. Curr Opin Genet Dev 11: 293-299, 2001.

52 Raval RR, Lau KW, Tran MGB, Sowter HM, Mandriota SJ, Li J-L, Pugh CW, Maxwell PH, Harris AL and Ratcliffe PJ: Contrasting properties of hypoxia-inducible factor 1 (HIF-1) and HIF-2 in von Hippel-Lindau-associated renal cell carcinoma. Mol Cell Biol 25: 5675.5686, 2005.

53 Greer SN, Metcalf JL, Wang Y and Ohh M: The updated biology of hypoxia-inducible factor. EMBO J 31: 2448-2460, 2012.

54 Carmeliet P and Jain RK: Angiogenesis in cancer and other diseases. Nature 407: 249-257, 2000.

55 Gray LH, Conger AD, Ebert M, Hornsey S and Scott OC. The concentration of oxygen dissolved in tissues at the time of irradiation as a factor in radiotherapy. Br J Radiol 26: 638-648, 1953.

56 Brizel DM, Scully SP, Harrelson JM, Layfield LJ, Bean JM, Prosnitz LR and Dewhirst MW: Tumor oxygenation predicts for the likelihood of distant metastases in human soft tissue sarcoma. Cancer Res 56: 941-943, 1996.

57 Minchinton AI and Tannock IF: Drug penetration in solid tumours. Nat Rev Cancer 6: 583-592, 2006.

58 Pires BR, Mencalha AL, Ferreira GM, Panis C, Silva, RC and Abdelhay E: The Hypoxia-Inducible Factor-1 [alpha] signaling pathway and its relation to cancer and immunology. Am J Immunol 10: 215-224, 2014.

59 Keith B and Simon MC: Hypoxia-Inducible Factors, stem cells, and cancer. Cell 129: 465-472, 2007.

60 Philip B, Ito K, Moreno-Sánchez R and Ralph SJ: HIF expression and the role of hypoxic microenvironments within primary tumours as protective sites driving cancer stem cell renewal and metastatic progression. Carcinogenesis 34: 16991707, 2013.

61 Jögi A, Øra I, Nilsson H, Lindeheim A, Makino Y, Poellinger L, Axelson H and Påhlman S: Hypoxia alters gene expression in human neuroblastoma cells toward an immature and neural crest-like phenotype. Proc Natl Acad Sci USA 99: 7021-7026, 2002.

62 Helczynska K, Kronblad Å, Jögi A, Nilsson E, Beckman S, Landberg $G$ and Påhlman $S$ : Hypoxia promotes a dedifferentiated phenotype in ductal breast carcinoma in situ. Cancer Res 63: 1441-1444, 2003. 
63 Heddleston JM, Li Z, McLendon RE, Hjelmeland AB and Rich $\mathrm{JN}$ : The hypoxic microenvironment maintains glioblastoma stem cells and promotes reprogramming towards a cancer stem cell phenotype. Cell Cycle 8: 3274-3284, 2009.

64 Cejudo-Martin P and Johnson RS: A new Notch in the HIF belt: How hypoxia impacts differentiation. Dev Cell 9: 575-576, 2005.

65 Schwab LP, Peacock DL, Majumdar D, Ingels JF, Jensen LC, Smith KD, Cushing RC and Seagroves TN: Hypoxia-inducible factor 1a promotes primary tumor growth and tumor-initiating cell activity in breast cancer. Breast Cancer Res 14: R6, 2012.

66 Krishnamachary B, Penet MF, Nimmagadda S, Mironchik Y, Raman V, Solaiyappan M, Semenza GL, Pomper MG and Bhujwalla ZM: Hypoxia regulates CD44 and its variant isoforms through hif- $1 \alpha$ in triple negative breast cancer. PLoS One 7: e44078, 2012.

67 Covello KL, Kehler J, Yu H, Gordan JD, Arsham AM, Hu CJ, Labosky PA, Simon MC and Keith B: HIF-2\{alpha\} regulates OCT-4: effects of hypoxia on stem cell function, embryonic development, and tumor growth. Genes Dev 20: 557-570, 2006.

68 Mathieu J, Zhang Z, Zhou W, Wang AJ, Heddleston JM, Pinna CMA, Hubaud A, Stadler B, Choi M, Bar M, Tewari M, Liu A, Vessella R, Rostomily R, Born D, Horwitz M, Ware C, Blau CA, Cleary MA, Rich JN and Ruohola-Baker H: HIF induces human embryonic stem cell markers in cancer cells. Cancer Res 71: 4640-4652, 2011.

69 Xing F, Okuda H, Watabe M, Kobayashi A, Pai SK, Liu W, Pandey PR, Fukuda K, Hirota S, Sugai T, Wakabayshi G, Koeda K, Kashiwaba M, Suzuki K, Chiba T, Endo M, Mo Y-Y and Watabe K: Hypoxia-induced JAGGED2 promotes breast cancer metastasis and self-renewal of cancer stem-like cells. Oncogene 30: 4075-4086, 2011.

70 Siveen KS, Sikka S, Surana R, Dai X, Zhang J, Kumar AP, Tan $\mathrm{BKH}$, Sethi $\mathrm{G}$ and Bishayee A: Targeting the STAT3 signaling pathway in cancer: role of synthetic and natural inhibitors. Biochim Biophys Acta 1845: 136-154, 2014.

71 Xie J, LeBaron MJ, Nevalainen MT and Rui H: Role of tyrosine kinase JAK2 in prolactin-induced differentiation and growth of mammary epithelial cells. J Biol Chem 277: 1402014030, 2002.

72 Marotta LLC, Almendro V, Marusyk A, Shipitsin M, Schemme J, Walker SR, Bloushtain-Qimron N, Kim JJ, Choudhury SA, Maruyama R, Wu Z, Gönen M, Mulvey LA, Bessarabova MO, Huh SJ, Silver SJ, Kim SY, Park SY, Lee HE, Anderson KS, Richardson AL, Nikolskaya T, Nikolsky Y, Liu XS, Root DE, Hahn WC, Frank DA and Polyak K: The JAK2/STAT3 signaling pathway is required for growth of $\mathrm{CD} 44{ }^{+} \mathrm{CD} 24^{-}$stem cell-like breast cancer cells in human tumors. J Clin Invest 121: 2723-2735, 2011.

73 Mohr A, Chatain N, Domoszlai T, Rinis N, Sommerauer M, Vogt $\mathrm{M}$ and Müller-Newen G: Dynamics and non-canonical aspects of JAK/STAT signalling. Eur J Cell Biol 91: 524-532, 2012.

74 Vuong T, Mallet J-F, Ouzounova M, Rahbar S, HernandezVargas H, Herceg Z and Matar C: Role of a polyphenolenriched preparation on chemoprevention of mammary carcinoma through cancer stem cells and inflammatory pathways modulation. J Transl Med 14: 13, 2016.

75 Zhang H, Cai K, Wang J, Wang X, Cheng K, Shi F, Jiang L, Zhang Y and Dou J: MiR-7, inhibited indirectly by lincRNA HOTAIR, directly inhibits SETDB1 and reverses the EMT of breast cancer stem cells by downregulating the STAT3 pathway. Stem Cells 32: 2858-2868, 2014.
76 Wei W, Tweardy DJ, Zhang M, Zhang X, Landua J, Petrovic I, Bu W, Roarty K, Hilsenbeck SG, Rosen JM and Lewis MT: STAT3 signaling is activated preferentially in tumor-initiating cells in claudin-low models of human breast cancer. Stem Cells 32: 2571-2582, 2014.

77 Ibrahim SA, Hassan H, Vilardo L, Kumar SK, Kumar AV, Kelsch R, Schneider C, Kiesel L, Eich HT, Zucchi I, Reinbold R, Greve B and Götte M: Syndecan-1 (CD138) modulates triple-negative breast cancer stem cell properties via regulation of LRP-6 and IL-6-mediated STAT3 signaling. PLoS One 8: e85737, 2013.

78 Hernandez-Vargas H, Ouzounova M, Le Calvez-Kelm F, Lambert MP, McKay-Chopin S, Tavtigian SV, Puisieux A, Matar C and Herceg Z: Methylome analysis reveals JAK-STAT pathway deregulation in putative breast cancer stem cells. Epigenetics 6: 428-439, 2011.

79 Wang X: STAT3 mediates resistance of CD44+CD24-/low breast cancer stem cells to tamoxifen in vitro. J Biomed Res 26: 325$335,2012$.

80 An H, Kim JY, Oh E, Lee N, Cho Y and Seo JH: Salinomycin promotes anoikis and decreases the CD44+/CD24- stem-like population via inhibition of STAT3 activation in MDA-MB-231 cells. PLoS One 10: e0141919, 2015.

81 Liu J, Pan S, Hsieh MH, Ng N, Sun F, Wang T, Kasibhatla S, Schuller AG, Li AG, Cheng D, Li J, Tompkins C, Pferdekamper A, Steffy A, Cheng J, Kowal C, Phung V, Guo G, Wang Y, Graham MP, Flynn S, Brenner JC, Li C, Villarroel MC, Schultz PG, Wu X, McNamara P, Sellers WR, Petruzzelli L, Boral AL, Seidel HM, McLaughlin ME, Che J, Carey TE, Vanasse G and Harris JL: Targeting WNT-driven cancer through the inhibition of Porcupine by LGK974. Proc Natl Acad Sci USA 110: 2022420229, 2013.

82 Lenz HJ and Kahn M: Safely targeting cancer stem cells via selective catenin coactivator antagonism. Cancer Sci 105: 10871092, 2014.

83 Jang G, Hong I, Kim R, Lee S-Y, Park S-J, Lee E-S, Park JH, Yun C, Chung J, Lee K-J, Lee H and Nam J: WNT/ $\beta$-Catenin small-molecule inhibitor CWP232228 preferentially inhibits the growth of breast cancer stem-like cells. Cancer Res 75: 16911702, 2015.

84 Fu YZ, Yan YY, He M, Xiao QH, Yao WF, Zhao L, Wu HZ, Yu ZJ, Zhou MY, Lv MT, Zhang SS, Chen JJ and Wei MJ: Salinomycin induces selective cytotoxicity to MCF-7 mammosphere cells through targeting the Hedgehog signaling pathway. Oncol Rep 35: 912-922, 2016.

85 LDE225 in Treating Patients With Stage II-III Estrogen Receptor- and HER2-Negative Breast Cancer. https:// clinicaltrials.gov/ct2/results?term=NCT01757327\&Search=Sear ch. Accessed 15 June 2016.

86 Schott AF, Landis MD, Dontu G, Griffith KA, Layman RM, Krop I, Paskett LA, Wong H, Dobrolecki LE, Lewis MT, Froehlich AM, Paranilam J, Hayes DF, Wicha MS and Chang JC: Preclinical and clinical studies of gamma secretase inhibitors with docetaxel on human breast tumors. Clin Cancer Res 19: 1512-1524, 2013.

87 Zhang CC, Yan Z, Zong Q, Fang DD, Painter C, Zhang Q, Chen E, Lira ME, John-Baptiste A and Christensen JG: Synergistic effect of the $\gamma$-secretase inhibitor PF-03084014 and docetaxel in breast cancer models. Stem Cells Transl Med 2: 233-242, 2013. 
88 Simões BM, O’Brien CS, Eyre R, Silva A, Yu L, SarmientoCastro A, Alférez DG, Spence K, Santiago-Gómez A, Chemi F, Acar A, Gandhi A, Howell A, Brennan K, Rydén L, Catalano S, Andó S, Gee J, Ucar A, Sims AH, Marangoni E, Farnie G, Landberg G, Howell SJ and Clarke RB: Anti-estrogen resistance in human breast tumors is driven by JAG1NOTCH4-dependent cancer stem cell activity. Cell Rep 12: 1968-1977, 2015.

89 Shim Y and Song JM: Quantum dot nanoprobe-based highcontent monitoring of notch pathway inhibition of breast cancer stem cell by capsaicin. Mol Cell Probes 29: 376-381, 2015.

90 Takebe N, Nguyen D and Yang SX: Targeting Notch signaling pathway in cancer: clinical development advances and challenges. Pharmacol Ther 141: 140-149, 2014

91 Yen WC, Fischer MM, Axelrod F, Bond C, Cain J, Cancilla B, Henner WR, Meisner R, Sato A, Shah J, Tang T, Wallace B, Wang M, Zhang C, Kapoun AM, Lewicki J, Gurney A and Hoey T: Targeting notch signaling with a NOTCH2/NOTCH3 antagonist (Tarextumab) inhibits tumor growth and decreases tumor-initiating cell frequency. Clin Cancer Res 21: 2084-2095, 2015.

92 Fuchs O: Transcription factor NF-kappaB inhibitors as single therapeutic agents or in combination with classical chemotherapeutic agents for the treatment of hematologic malignancies. Curr Mol Pharmacol 3: 98-122, 2010.

93 Gilmore TD and Garbati MR: Inhibition of NF-kB signaling as a strategy in disease therapy. Curr Top Microbiol Immunol 349: 245-263, 2011

94 Hinohara K, Kobayashi S, Kanauchi H, Shimizu S, Nishioka K, Tsuji E, Tada K, Umezawa K, Mori M, Ogawa T, Inoue J, Tojo A and Gotoh N: ErbB receptor tyrosine kinase/NF-kB signaling controls mammosphere formation in human breast cancer. Proc Natl Acad Sci USA 109: 6584-6589, 2012.

95 Lock FE, McDonald PC, Lou Y, Serrano I, Chafe SC, Ostlund C, Aparicio S, Winum J-Y, Supuran CT and Dedhar S: Targeting carbonic anhydrase IX depletes breast cancer stem cells within the hypoxic niche. Oncogene 32: 5210-5219, 2013.
96 Folkman J and Folkman J: Angiogenesis: an organizing principle for drug discovery? Nat Rev Drug Discov 6: 273-286, 2007.

97 Bergers $G$ and Hanahan D: Modes of resistance to antiangiogenic therapy. Nat Rev Cancer 8: 592-603, 2008.

98 Hayes DF: Bevacizumab treatment for solid tumors: boon or bust? JAMA 5: 506, 2011.

99 Conley SJ, Gheordunescu E, Kakarala P, Newman B, Korkaya $\mathrm{H}$, Heath AN, Clouthier SG and Wicha MS: Antiangiogenic agents increase breast cancer stem cells via the generation of tumor hypoxia. Proc Natl Acad Sci USA 109: 2784-2789, 2012.

100 Korkaya H, Paulson A, Charafe-Jauffret E, Ginestier C, Brown M, Dutcher J, Clouthier SG and Wicha MS: Regulation of mammary stem/progenitor cells by PTEN/Akt/beta-catenin signaling. PLoS Biol 7: e1000121, 2009.

101 Lee JH, Shim JW, Choi YJ, Heo K and Yang K: The combination of sorafenib and radiation preferentially inhibits breast cancer stem cells by suppressing HIF-1 $\alpha$ expression. Oncol Rep 29: 917-924, 2013.

102 Harrison H, Rogerson L, Gregson HJ, Brennan KR, Clarke RB and Landberg G: Contrasting hypoxic effects on breast cancer stem cell hierarchy is dependent on ER- $\alpha$ status. Cancer Res 73: 1420-1433, 2013.

103 Chung SS, Giehl N, Wu Y and Vadgama J V.: STAT3 activation in HER2-overexpressing breast cancer promotes epithelialmesenchymal transition and cancer stem cell traits. Int J Oncol 44: 403-411, 2014.

104 Sehl ME, Shimada M, Landeros A, Lange K and Wicha MS: Modeling of cancer stem cell state transitions predicts therapeutic response. PLoS One 10: e0135797, 2015.

Received July 21, 2016

Revised August 16, 2016

Accepted August 18, 2016 